\title{
Basketbol Hakemlerinin Fiziksel Öz Saygıları ile Öz Yeterlilikleri Arasındaki İlişkinin İncelenmesi
}

\author{
Niyazi Sıdkı ADIGÜZEL ${ }^{1 *}$ \\ ${ }^{1}$ Spor Uzmant, https://orcid.org/0000-0002-1201-2784
}

\section{Öz}

Orijinal Makale

Araştırmanın amacı basketbol hakemlerinin fiziksel öz saygı düzeyleri ile öz yeterlik düzeyleri arasındaki ilişkinin incelenmesidir. Araştırma ilişkisel tarama modelinde betimsel bir çalışmadır. Araștırmanın evrenini 2017-2018 y1lında Ankara ilinde aktif olarak basketbol hakemliği yapan hakemler oluşturmaktadır. Araştırmada evrenin tamamı örnekleme dahil edilmiştir. Araştırmaya katılan hakem grubunu \%19'u (n = 22) kadın ve \%81'i $(n=93)$ erkek olmak üzere 115 hakem oluşturmuştur. Araştırmada veri toplama aracı olarak kişisel bilgi formu, Karaçam (2016) tarafindan Türkçe uyarlaması yapılan Fiziksel Saygı Ölçeği (FSÖ) ve Karaçam ve Pulur (2017) tarafindan geliştirilen Hakem Öz Yeterlik Ölçeği (HÖYÖ) kullanılmıştır. Değişkenler arası ilişkilerin belirlenmesi için Pearson Momentler Çarpımı Korelasyon Katsayısı, hakemlerin cinsiyete göre karşıllaştırılmasında t testi kullanılmıştır. Basketbol hakemlerinin FSÖ alt faktörü olan atıf puanı, HÖYÖ toplam puan ve HÖYÖ alt faktörleri ile hakemlerin yaşları ve hakemlik yılları arasında pozitif yönlü ve anlamlı ilişki olduğu görülmüştür. Basketbol hakemlerinin FSÖ toplam puan ve alt faktörleri, HÖYÖ toplam puan ve HÖYÖ alt faktörleri arasında bütün değişkenlerin birbiriyle pozitif yönlü ve anlamlı ilişskili oldukları görülmüştür. Sonuç olarak basketbol hakemlerinin yaşları ve hakemlik yıllarının hakemlerin atıf, öz yeterlik ve öz yeterlik alt faktörleri üzerinde önemli değişkenler olduğu ve basketbol hakemlerinin fiziksel öz saygı ve hakem öz yeterlik düzeylerinin birbirini pozitif yönde etkilediği sonucuna ulaşılmıştır.

\section{Examining the Relationship between Basketball Referees' Physical Self- Esteem and Self-Efficacy}

\begin{abstract}
The aim of the study is to investigate the relationship between basketball referees' physical self-esteem and self-efficacy levels. The research design is defined as relational screening design. The universe of the study consists referees who actively served in Ankara in 2017-2018 and the whole universe was included in the sample. The participants of the study consisted of a total of 115 referees, 19\% ( $n=22)$ females and $81 \%(n=93)$ males. In the study, a demographic information form, the Physical Esteem Scale (PES) which was adapted by Karaçam (2016) and the Referee Self-Efficacy Scale (REFS) which was developed by Karaçam and Pulur (2017) were used as data collection tools. Pearson Product Moment Correlation Coefficient was used to determine the relationship between variables, and t-test was used to compare the referees by gender A positive and significant relationship was found between referees' reference score, which is one of the subscales of PES, REFS total score and its subscales and referees' ages and refereeing experiences. All variables were found to be positively and significantly correlated with PES total score and its subscales and REFS total score and its subscales. As a result, it was concluded that ages and refereeing experience of the referees were significant variables on attribution, self-efficacy and the sub-factors of self-efficacy and that basketball referees' physical selfesteem and self-efficacy levels positively affected each other.
\end{abstract}

Original Article

$\underline{\text { Article Info }}$ Received:13.11.2018

Accepted: 21.12.2018

Online Published: 31.12.2018

\author{
(nelimeler: \\ Fiziksel Öz Saygl, \\ Hakem Öz Yeterliği, \\ Öz Yeterlik, Hakem
}




\section{GíRiș}

Basketbol hakemleri, müsabaka sırasında görevlerini başarıyla yerine getirmek ve kararlarında hata yapmamak için seyirci, oyuncu ve kulüp baskısına rağmen görevlerini en iyi şekilde yerine getirmek zorundadır. Hakemler, olumsuz koşullar ve baskı altında, maç sırasında gerçekleşen eylemleri değerlendirmeli ve yargılamalı, hızlı kararlar almalı, oyunu yönetmeli, doğru iletişim kurmalı, oyunun birden çok yönüne dikkat etmeli, düzenini sürdürmeli, fiziksel ve mental olarak en üst performansı göstermeli, anlaşmazlıkları ve problemleri çözmelidir (Karaçam ve Pulur, 2016; Tuero, Tabernero, Marquez ve Guillen, 2002). Basketbol hakemleri bu görevlerde yetersizlik, dikkatsizlik, yanlış kararlar, gecikmeli tepkiler verirlerse bu durum onları nihai stres ve tükenmişliğe sürükleyebilir (Ekmekçi, 2008; Ekmekçi, 2016; Guillén ve Feltz, 2011). Ayrıca basketbol hakemleri sadece müsabaka esnasında değil müsabaka öncesi ve sonrasında seyirci, oyuncu ve kulüp baskısına maruz kalmaktadırlar. Bu nedenle basketbol hakemlerin yaptıkları iş oldukça zor ve yıpratıcıdır. Basketbol hakemleri tüm bu olumsuz etkenlere rağmen güçlü bir karakter ve başarılı bir performans göstermek zorundadır (Karaçam ve Pulur 2017a).

$\mathrm{Bu}$ bağlamda basketbol hakemlerinin performansını etkileyen değişkenlerin bilinmesi oldukça önemlidir. Basketbol hakemlerinin performansının belirlenmesi ve performansı etkileyen değişkenlerin bilinmesi hakem eğitim süreçlerinin planlanmasında ve hakem performansının yükseltilmesinde fayda sağlayacaktır (Karaçam ve Pulur 2017a). Guillén ve Feltz (2011), Karaçam ve Pulur (2017a), ve Myers, Feltz, Guillén ve Dithurbide, (2012) hakem yeterlik alanlarının oyun bilgisi ve stratejik beceriler, karar verme becerileri, psikolojik beceriler, oyunun iletişimi, denetimi ve fiziksel uygunluk olarak belirtmişlerdir. Ayrıca yapılan bazı çalışmalarda hakemlerin bazı pozitif inançlarının onların performanslarına olumlu yönde etki edeceği sonucuna ulaşılmıştır (Guillén ve Feltz 2011; Karaçam ve Pulur 2016; Karaçam ve Pulur 2017b; Karaçam ve Pulur 2017c; Karaçam ve Pulur 2018; Myers ve ark., 2012). Bu bağlamda hakem yeterlik alanları ve yapılan araştırmalar incelendiğinde hakemlerin performansını etkileyeceği düşünülen pozitif psikoloji değişkenlerinden fiziksel öz saygı ve öz yeterlik bu çalışmada ele alınmıştır.

Fiziksel öz sayg1, öz saygının önemli bir boyutudur. Kişinin vücut görünüşüne yönelik öz değerlendirmesi olarak ifade edilir (Adams, Turner ve Bucks, 2005; Mendelson, Mendelson ve White, 2001). Schilder (1950) ise fiziksel saygıyı, zihnimizde biçimlendirdiğimiz kendi vücudumuzun resmidir, yani kendimize nasıl göründüğümüzdür şeklinde tanımlamıştır. Bedenin farklı bölümlerinin kişiye verdiği memnuniyet kişinin kendine güveniyle ilişkilidir. Kişilerin antropometrik özelliklerinin (yaş, boy, kilo) yanısıra sağlık durumu, fiziksel görünüşü, kendine verdiği değeri, kişinin becerilerini kontrol eden kendine karş1 davranışlarını oluşturmakta ve bütün bunlar sosyal ilişkilerine yansımaktadır (Uğur, 1996). İlgili alan yazın incelendiğinde hakemlerin fiziksel öz saygılarını inceleyen çalışmaya rastlanamamıştır. Ancak bazı meslek gruplarına yönelik çalışmalarda fiziksel öz saygının kişilerin iş başarılarıyla ilişskili olduğu sonucuna ulaşılmıştır (Karaçam, Pulur ve Adıgüzel, 2017). Buradan hareketle basketbol hakemlerinin fiziksel öz saygı düzeyleri ve bunu etkileyen değişkenlerin bilinmesinin önemli olduğu düşünülmektedir.

Hakem öz yeterliği, Bandura'nın öz yeterlik teorisi (Bandura, 1997) ve daha spesifik olarak sporda öz yeterlik içinde kavramsallaştırılmıştır (Feltz, Short ve Sullivan, 2008). Hakem öz yeterliği hakemlerin işlerinde başarılı bir şekilde performans kapasitesine sahip olduklarına 
yönelik inanç derecesi olarak tanımlanmıştır (Guillén ve Feltz 2011). Guillén ve Feltz (2011) kendi kendini yeterlik teorisinden ve sporda öz yeterlik araştırmasından yola çıkarak, öz yeterliği yüksek hakemlerin kararlarında daha doğru ve performanslarında daha etkili olduklarını belirtmişlerdir. Bunun yanında antrenörlerden, yöneticilerden ve diğer yetkililerden daha fazla saygı gördükleri ve öz yeterliği düşük hakemlere göre daha az stres yaşadıklarını belirtmişlerdir. Ayrıca Farshad ve ark., (2013) ile Guillén ve Feltz (2011) öz yeterliği yüksek hakemlerin mesleğe daha fazla bağlı olduklarını ve bu durumun hakemlik performansını olumlu yönde etkilediğini belirtmişlerdir. Hepler ve Feltz (2012) yaptıkları çalışmada öz yeterlik düzeyinin karar vermede önemli bir etkisinin olduğunu bu durumunda hakem performansını olumlu yönde etkilediğini belirtmişlerdir. Ayrıca Karaçam ve Pulur (2017a), Karaçam ve Pulur (2017b), Karaçam ve Pulur (2017c), Myers ve ark., (2012) yaptıkları çalışmalarda hakemlerin öz yeterlik düzeyleriyle yaşları ve hakemlik tecrübeleri arasında pozitif yönlü bir ilişki bulmuşlar ve hakemlerin yaş ve deneyimleri arttıkça öz yeterlik düzeylerinin de arttığını belirtmişlerdir. Spencer (2015) yaptı̆̆ı çalışmada hakemlerin performanslarının en önemli yordayıcısının tecrübe olduğunu belirtmiştir.

Yukarıda incelenen araştırmalardan yola çıkıldığında basketbol hakemlerinin fiziksel öz saygı ve hakem öz yeterliğini etkileyen değişkenlerin ve bu değişkenler arasındaki ilişkilerin bilinmesi hakem eğitim sürecinin planlanmasında, müsabakaların başarılı bir şekilde yönetilmesinde ve hakem performansının yükseltilmesinde oldukça önemli olduğu görülmektedir. Bu nedenle bu çalışmada basketbol hakemlerinin fiziksel öz saygı düzeyleri ve öz yeterlik düzeyleri arasındaki ilişkinin incelenmesi amaçlanmıştır.

\section{YÖNTEM}

\section{Araştırma Modeli}

Basketbol hakemlerinin öz yeterlik düzeyleri ile fiziksel öz sayg1 düzeyleri arasındaki ilişkinin incelenmesini amaçlayan bu araştırma ilişkisel tarama modelinde betimsel bir araştırmadır. İlişkisel araştırmalar her ne kadar gerçek anlamda bir nedenselliğin varlığını kanıtlamasa da bazı ileri düzey istatistik tekniklerinin kullanılmasıyla ilişkisel araştırmalarla neden-sonuç ilişkisine yönelik çıkarımlarda bulunmak mümkün olabilmektedir (Fraenkel ve Wallen, 2009).

\section{Çalışma Grubu}

Araştırmanın evrenini 2017-2018 yllında Ankara ilinde aktif olarak basketbol hakemliği yapan saha hakemler oluşturmaktadır. Araştırmada evrenin tamamı örnekleme dahil edilmiştir. Örnekleme yöntemi olarak evren örneklem yöntemi kullanılmıştır. Araştırmaya katılan hakem grubunu \%19'u (n=22) kadın ve \%81'i (n=93) erkek olmak üzere 115 hakem oluşturmuştur. Araştırmaya katılan hakemlerin yaş ortalanması 29, hakemlik tecrübeleri ortalama 9 yıldır. Araştırmaya katılan hakemlere ölçme araçları müsabakalarının olmadı̆̆ı bir zamanda yüz yüze uygulanmıştır. 


\section{Veri Toplama Aracı}

Hakemlerin hakem öz yeterlik düzeylerinin belirlenmesi için Karaçam ve Pulur (2017a) tarafından geliştirilen Hakem Öz Yeterlik Ölçeği (HÖYÖ) ve hakemlerin fiziksel öz saygıları nı ölçmek için Karaçam (2016) tarafından Türkçe uyarlaması yapılan Fiziksel Saygı Ölçeği (FSÖ) kullanılmıştır.

Hakem Öz, Yeterlik Ölçeği (HÖŸ̈): Hakem Öz Yeterlik Ölçeği (HÖYÖ) Karaçam ve Pulur (2017) tarafından yapılmıştır. Ölçeğin beşli likert tipi dereceleme biçiminde oluşturulmuş 18 maddesi bulunmaktadır. Ölçekte 5 maddeden oluşan fiziksel yeterlik, 3 maddeden oluşan oyun bilgisi, 3 maddeden oluşan karar verme, 3 maddeden oluşan baskı ve 4 maddeden oluşan iletişim olmak üzere beş alt faktörü vardır. Ölçekte ters puanlanan madde bulunmamaktadır. Ölçeğin her bir faktöründen alınan yüksek puanlar, o faktördeki öz yeterliğin yüksek olduğunu göstermektedir. Karaçam ve Pulur (2017a) tarafından yapılan analizlerde tüm ölçek için açıklanan varyansın \%72.27 olduğu görülmüştür. Öz değerleri 1'den büyük beş bileşenli bir yapı ortaya çıkmıştır. Ölçek bileşenleri için alfa iç tutarlık katsayılarının fiziksel yeterlik faktöründe .88 , oyun bilgisi faktöründe .71, karar verme faktöründe .85 , bask1 faktörü .88 , iletişim faktöründe .81 ve ölçeğin tümü için .90 olduğu görülmüştür. KMO değerinin ise .86 olduğu görülmüştür. Ölçeğe uygulanan DFA analizi sonucunda $\chi^{2} / \mathrm{sd}=1.842$ RMSEA $=.06$, CFI $=.94$, GFI $=.88$, RMR $=.01$ olduğu görülmüştür.

$\mathrm{Bu}$ çalışma için yapılan analizlerde tüm ölçek için açıklanan varyansın \%71.13 olduğu görülmüştür. Öz değerleri 1'den büyük beş bileşenli bir yap1 ortaya çıkmıştır. Ölçek bileşenleri için alfa iç tutarlık katsayılarının fiziksel yeterlik faktöründe .85 , oyun bilgisi faktöründe .70 , karar verme faktöründe .85 , bask1 faktörü .80 , iletişim faktöründe .82 ve ölçeğin tümü için .90 olduğu görülmüştür. KMO değerinin ise .85 olduğu görülmüştür. Ölçeğe uygulanan DFA analizi sonucunda $\chi^{2} / \mathrm{sd}=1.971 \mathrm{RMSEA}=.06, \mathrm{CFI}=.94$, GFI $=$ $.96, \mathrm{RMR}=.01$ olduğu görülmüştür.

Fiziksel saygı ölçeği (FSÖ): Fiziksel saygı ölçeği (FSÖ) Confalonieri vd. (2008) tarafından geliştirilen ve Karaçam (2016) tarafından Türkçeye uyarlanan FSÖ kullanılmıştır. Ölçeğin beşli likert tipi dereceleme biçiminde oluşturulmuş 12 maddesi bulunmaktadır. Ölçekte 5 maddeden oluşan görünüm, 3 maddeden oluşan kilo ve 4 maddeden oluşan atıf olmak üzere üç alt boyutu vardır. Ölçekte 2, 4, 6, 8, 10, 12 numaralı maddeler ters puanlanır. Ölçekten alınan yüksek puan fiziksel saygı seviyesinin yüksek olduğunu gösterir. FSÖ için açıklanan varyansın \% 57.76 olduğu görülürken Ölçeğin geçerlilik güvenirlik çalışmalarında, görünüm alt boyutunun iç tutarlılığı .73, kilo alt boyutunun iç tutarlılı̆̆ .76 ve atıf alt boyutunun iç tutarlılığı .64 olarak belirlenmiştir. FSÖ’nun 3 faktörlü yapısının doğrulanması için yapılan DFA sonuçları modelin iyilik uyum indekslerinin kabul edilebilir düzeyde olduğunu göstermiştir $\left(\chi^{2} / \mathrm{sd}=3.69, \mathrm{RMSEA}=.087, \mathrm{CFI}=.89, \mathrm{GFI}=.92\right)$.

Bu çalışma için yapılan analizlerde FSÖ için açıklanan varyansın \% 55.41 olduğu görülürken Ölçeğin geçerlilik güvenirlik çalışmalarında, görünüm alt boyutunun iç tutarlılığı .70, kilo alt boyutunun iç tutarlılığı .78 ve atıf alt boyutunun iç tutarlılı̆̆ .69 olarak belirlenmiştir. 
FSÖ'nun 3 faktörlü yapısının doğrulanması için yapılan DFA sonuçları modelin iyilik uyum indekslerinin kabul edilebilir düzeyde olduğunu göstermiştir $\left(\chi^{2} / \mathrm{sd}=2.51\right.$, RMSEA $=.07$, $\mathrm{CFI}=.90, \mathrm{GFI}=.94, \mathrm{RMR}=.01)$.

\section{Verilerin Analizi}

Verilerin analizinde öncelikli olarak veri seti hatalı değer, aykırı değer, normallik ve çoklu bağıntı açısından incelenmiştir. Bu süreçte hatalı olarak girilen veri olmadığı gözlenmiştir. Verilerin çözümlenmesi SPSS 21 programı kullanılarak yapılmıştır. Değişkenler arası ilişkilerin belirlenmesi için Pearson Momentler Çarpımı Korelasyon katsayısı, hakemlerin cinsiyete göre karşılaştırılmasında t testi kullanılmıştır. Anlamlılık düzeyi $\mathrm{p}<.05$ olarak alınmıştır.

\section{BULGULAR}

Tablo 1. Basketbol hakemlerinin FSÖ toplam puan ve alt faktörleri ile HÖYÖ toplam puan ve alt faktörlerinin cinsiyete göre $t$ testi sonuçları

\begin{tabular}{|c|c|c|c|c|c|c|c|}
\hline \multirow[t]{2}{*}{ Değișkenler } & \multicolumn{2}{|c|}{$\begin{array}{l}\text { Kadın } \\
(n=22)\end{array}$} & \multicolumn{2}{|c|}{$\begin{array}{l}\text { Erkek } \\
(n=93)\end{array}$} & \multirow[t]{2}{*}{$t$} & \multirow[t]{2}{*}{$s d$} & \multirow[t]{2}{*}{$P$} \\
\hline & $\bar{X}$ & $S$ & $\bar{X}$ & $S$ & & & \\
\hline FSÖ toplam & 36.04 & 7.20 & 36.43 & 7.87 & .20 & 113 & .83 \\
\hline Görünüm & 16.81 & 2.88 & 36.43 & 7.87 & .10 & 113 & .91 \\
\hline Kilo & 8.36 & 2.66 & 8.17 & 3.11 & .26 & 113 & .79 \\
\hline Atıf & 10.86 & 3.05 & 11.36 & 3.26 & .65 & 113 & .51 \\
\hline HÖYÖ toplam & 85.36 & 4.28 & 86.63 & 6.01 & .93 & 113 & .35 \\
\hline Fiziksel yeterlik & 23.67 & 1.70 & 23.68 & 2.15 & .01 & 113 & .98 \\
\hline Oyun Bilgisi & 14.36 & .95 & 14.63 & 1.15 & 1.01 & 113 & .31 \\
\hline Karar Verme & 14.06 & .90 & 14.26 & 1.43 & .93 & 113 & .35 \\
\hline Baskı & 14.25 & .39 & 14.81 & 1.30 & 1.97 & 113 & .06 \\
\hline İletişim & 18.98 & 1.28 & 19.13 & 1.44 & .43 & 113 & .66 \\
\hline
\end{tabular}

Basketbol hakemlerinin fiziksel öz saygı ve öz yeterlik düzeylerinin cinsiyete göre t-testi sonuçlarına ilişkin tablo 1 incelendiğinde, FSÖ toplam, görünüm, kilo ve atıf alt faktörleri ile hakemlerin cinsiyetleri arasında anlamlı bir fark olmadığ görülmüştür $(p>.05)$. HÖYÖ toplam, fiziksel yeterlik, oyun bilgisi, karar verme, baskı ve iletişim alt faktörleri ile hakemlerin cinsiyetleri arasında anlamlı bir fark olmadığı görülmüştür $(\mathrm{p}>.05)$. Başka bir anlatımla cinsiyet, basketbol hakemlerinin fiziksel öz saygı ve öz yeterlik düzeyleri üzerinde belirleyici bir değişken değildir. 
Tablo 2. Basketbol hakemlerinin FSÖ toplam puan ve alt faktörleri ile HÖYÖ toplam puan ve alt faktörlerinin yaş ve hakemlik yılı korelasyon sonuçları

\begin{tabular}{|c|c|c|c|}
\hline Değişkenler & $N$ & Yaş & Hakemlik yılı \\
\hline FSÖ toplam & 115 & .14 & .10 \\
\hline Görünüm & 115 & .09 & .07 \\
\hline Kilo & 115 & .01 & .01 \\
\hline Atıf & 115 & $.24^{* *}$ & $.19^{*}$ \\
\hline HÖYÖ toplam & 115 & $.33^{* *}$ & $.33^{* *}$ \\
\hline Fiziksel yeterlik & 115 & $.28^{* *}$ & $.28^{* *}$ \\
\hline Oyun Bilgisi & 115 & $.23^{* *}$ & $.26 * *$ \\
\hline Karar Verme & 115 & $.24^{* *}$ & $.25^{* *}$ \\
\hline Baskı & 115 & $.34^{* *}$ & $.32^{* *}$ \\
\hline İletişim & 115 & $.21 * *$ & $.22^{* *}$ \\
\hline
\end{tabular}

$* * \mathrm{p}<.01, * \mathrm{p}<.05$

Basketbol Hakemlerinin FSÖ toplam puan ve alt faktörleri ile HÖYÖ toplam puan ve alt faktörlerinin yaş ve hakemlik yılı korelasyon sonuçları 2'de verilmiştir. Hakemlerin FSÖ toplam puan, görünüm ve atıf alt faktörleri ile yaşları ve hakemlik yılları arasında anlamlı ilişki olmadığg görülmektedir. FSÖ alt faktörü olan atıf ile yaş $(r=.24, p<.01)$ ve hakemlik y1lı $(\mathrm{r}=.51, \mathrm{p}<.05)$ arasında pozitif yönlü ve anlamlı ilişki olduğu görülmektedir. HÖYÖ toplam puan $(r=.33, p<.01)$ ve HÖYÖ alt faktörleri ile hakemlerin yaşları arasında pozitif yönlü ve anlamlı ilişki olduğu görülmektedir. HÖYÖ alt faktörleri ile yaş arasındaki en yüksek ilişkinin baskı $(r=.34, p<.01)$, en düşük ilişkinin iletişim $(r=.21, p<.01)$ puanları arasında olduğu görülmektedir. HÖYÖ toplam puan $(r=.33, p<.01)$ ve HÖYÖ alt faktörleri ile hakemlerin hakemlik yılı arasında pozitif yönlü ve anlamlı ilişki olduğu görülmektedir. HÖYÖ alt faktörleri ile hakemlik yılı arasındaki en yüksek ilişkinin baskı $(r=.32, p<.01)$, en düşük ilişkinin iletişim $(r=.22, p<.01)$ puanları arasında olduğu görülmektedir.

Tablo 3. Basketbol hakemlerinin FSÖ toplam puan ve alt faktörleri ile HÖYÖ toplam puan ve alt faktörleri arasındaki korelasyon

\begin{tabular}{|c|c|c|c|c|c|c|c|c|c|c|}
\hline Değişkenler & 1 & 2 & 3 & 4 & 5 & 6 & 7 & 8 & 9 & 10 \\
\hline 1. FSÖ toplam & 1.00 & $.83^{* *}$ & $.86^{* *}$ & $.83^{* *}$ & $.41^{* *}$ & $.38^{* *}$ &. $\mathbf{3 0}^{* *}$ & $.26^{* *}$ & $.27^{* *}$ & $.38^{* *}$ \\
\hline 2. Görünüm & & 1.00 & $.62^{* * *}$ & $.51^{* *}$ & $.40^{* * *}$ & $.36^{* * *}$ & $.28^{* *}$ & $.29^{* *}$ & $.26^{* *}$ & $.38^{* * *}$ \\
\hline 3. Kilo & & & 1.00 & $.55^{* *}$ & $.28^{* *}$ & $.29^{* *}$ & $.20 *$ & $.22^{* *}$ & $.21^{* *}$ & $.27^{* *}$ \\
\hline 4. AtIf & & & & 1.00 & $.35^{* *}$ & $.31^{* *}$ & $.26 *$ & $.25^{* *}$ & $.22^{* *}$ & $.32^{* *}$ \\
\hline 5. HÖYÖ toplam & & & & & 1.00 & $.81^{* *}$ & $.82^{* * *}$ & $.86^{* *}$ & $.74^{* *}$ & $.73^{* * *}$ \\
\hline 6. Fiziksel yeterlik & & & & & & 1.00 & $.62^{* * *}$ & $.65^{* *}$ & $.39^{* * *}$ & $.39^{* *}$ \\
\hline 7. Oyun Bilgisi & & & & & & & 1.00 & $.67^{* *}$ & $.55^{* *}$ & $.50^{* *}$ \\
\hline 8. Karar Verme & & & & & & & & 1.00 & $.59^{* *}$ & $.53^{* *}$ \\
\hline 9. Baskı & & & & & & & & & 1.00 & $.57^{* * *}$ \\
\hline 10. İletişim & & & & & & & & & & 1.00 \\
\hline
\end{tabular}

Basketbol Hakemlerinin FSÖ toplam puan ve alt faktörleri ile HÖYÖ toplam puan ve alt faktörleri arasındaki korelasyon sonuçları tablo 3'te verilmiştir. Basketbol hakemlerinin FSÖ toplam puan ve alt faktörleri, HÖYÖ toplam puan ve HÖYÖ alt faktörleri arasındaki ilişkileri gösteren tablo incelendiğinde bütün değişkenlerin birbiriyle pozitif yönlü ve anlamlı ilişkili oldukları görülmektedir. Hakemlerin FSÖ toplam puanı ile HÖYÖ toplam puanı ve alt 
faktörleri arasındaki en yüksek ilişkinin HÖYÖ toplam puan $(r=.41, p<.01)$ arasında olduğu görülmektedir.

\section{TARTIŞMA VE SONUÇ}

Araştırmada basketbol hakemlerinin öz yeterlik düzeyleri ile fiziksel öz saygı düzeyleri arasındaki ilişki cinsiyet değişkeniyle birlikte incelenmiştir. Basketbol hakemlerinin fiziksel öz saygı toplam puan, görünüm, kilo ve atıf alt faktörleri ile hakemlerin cinsiyetleri arasında anlamlı bir fark olmadığ 1 görülmüştür. Bu durum basketbol hakemlerinin cinsiyetlerinin fiziksel öz saygıları üzerinde önemli bir etkiye sahip olmadı şeklinde yorumlanabilir. Yapılan ayrıntılı alan yazın taramasına rağmen basketbol hakemlerinin fiziksel öz saygı düzeyleri ile cinsiyetleri arasındaki ilişkiyi inceleyen çalışmaya rastlanamamıştır. Ancak Karaçam (2016), Karaçam ve ark., (2017) ve Karaçam ve Adigüzel (2016) beden eğitimi öğretmenleri üzerine yaptıkları çalışmalarda cinsiyet ile fiziksel öz saygı düzeyleri arasında çalışmanın paralelinde sonuçlara ulaşmıştır. Çalışmanın aksine Dotse ve Asumeng (2015) yaptıkları çalışmada cinsiyet ile fiziksel saygı arasında erkekler lehine anlamlı bir fark olduğunu bulmuşlardır. Alan yazındaki bu farklılıkların çalışılan meslek gruplarının kendine özgü özelliklerinden ve çalışılan grubun kendine özgü özelliklerinden kaynaklandığı düşünülmektedir.

Basketbol hakemlerinin HÖYÖ toplam, fiziksel yeterlik, oyun bilgisi, karar verme, baskı ve iletişim alt faktörleri ile hakemlerin cinsiyetleri arasında anlamlı bir fark olmadığ görülmüştür. Ancak çalışmanın aksine Karaçam ve Pulur (2017b) ve Karaçam ve Pulur (2017c) hakemler üzerine yaptıkları çalışmalarda hakemlerin cinsiyetleri ile öz yeterlikleri arasında erkek hakemler lehine anlamlı fark bulmuşlardır. Alan yazındaki bu farklılığın çalışılan hakem gruplarının kendine özgü yapısından kaynaklandığg düşünülmektedir.

Basketbol hakemlerinin FSÖ toplam puan, görünüm ve atıf alt faktörleri ile yaşları ve hakemlik yılları arasında anlamlı ilişki olmadığı görülmektedir. FSÖ alt faktörü olan atıf ile yaş ve hakemlik yılı arasında pozitif yönlü ve anlamlı ilişki olduğu görülmektedir. Yapılan ayrıntılı alan yazın taramasına rağmen basketbol hakemlerinin fiziksel öz saygı düzeyleri ile yaş ve kıdemleri arasındaki ilişkiyi inceleyen çalışmaya rastlanamamıştır. Karaçam (2016), Karaçam ve ark., (2017) ve Karaçam ve Adıgüzel (2016) beden eğitimi öğretmenleri üzerine yaptıkları çalışmalarda cinsiyet ile fiziksel öz saygı düzeyleri arasında çalışmanın paralelinde sonuçlara ulaşmıştır. Araştırma bu yönüyle alan yazındaki diğer çalışmalarla paralellik göstermektedir.

Basketbol hakemlerinin HÖYÖ toplam puan ve HÖYÖ alt faktörleri ile hakemlerin yaşları arasında pozitif yönlü ve anlamlı ilişki olduğu görülmektedir. HÖYÖ alt faktörleri ile yaş arasındaki en yüksek ilişkinin baskı, en düşük ilişkinin iletişim puanları arasında olduğu görülmektedir. Bu durum hakemlerin yaşları arttıkça öz yeterliklerinin de arttığı şeklinde yorumlanabilir. Karaçam ve Pulur (2017a), Karaçam ve Pulur (2017b), Karaçam ve Pulur (2017c) ile Myers ve ark., (2012) yaptıkları çalışmalarda çalışmaya benzer şekilde HÖYÖ toplam puanı ve ölçeğin tüm alt boyutları ile yaş arasında pozitif yönlü ve anlamlı ilişki bulmuşlardır. Araştırma bu yönüyle alan yazındaki diğer çalışmalarla paralellik göstermektedir.

HÖYÖ toplam puan ve HÖYÖ alt faktörleri ile hakemlerin hakemlik yılı arasında pozitif yönlü ve anlamlı ilişki olduğu görülmektedir. HÖYÖ alt faktörleri ile hakemlik yılı arasındaki en yüksek ilişkinin baskı, en düşük ilişkinin iletişim puanları arasında olduğu görülmektedir. Karaçam ve Pulur (2017a), Karaçam ve Pulur (2017b), Karaçam ve Pulur (2017c) ile Myers ve ark., (2012) yaptıkları çalışmalarda çalışmaya benzer şekilde HÖYÖ toplam puanı ve ölçeğin tüm alt boyutları ile hakemlik yılları arasında pozitif yönlü ve anlamlı ilişki bulmuşlardır. Guillén ve Feltz (2011) yaptığı çalışmada hakemlerin hakemlik 
deneyimlerinin hakemlerin öz yeterlikleri üzerinde etkili olduğunu belirtmişlerdir. Çalışma bu yönüyle alan yazındaki diğer çalışmalarla paralellik göstermektedir.

Basketbol hakemlerinin FSÖ toplam puan ve alt faktörleri, HÖYÖ toplam puan ve HÖYÖ alt faktörleri arasında tüm değişkenlerin birbiriyle pozitif yönlü ve anlamlı ilişkili oldukları görülmektedir. Hakemlerin FSÖ toplam puanı ile HÖYÖ toplam puanı ve alt faktörleri arasındaki en yüksek ilişkinin HÖYÖ toplam puan arasında olduğu görülmektedir. Ayrıntılı alan yazın taraması yapılmasına rağmen hakemlerin fiziksel öz saygıları ile öz yeterlikleri arasındaki ilişkiyi inceleyen çalışmaya rastlanamamıştır. Araştırma bu yönüyle alan yazına katkı sağlayacağı düşünülmektedir.

Araştırma sonucunda basketbol hakemlerinin yaşları ve hakemlik yıllarının hakemlerin fiziksel öz saygı alt faktörü olan atıf, öz yeterlik ve öz yeterlik alt faktörleri üzerinde önemli değişkenler olduğu görülmüştür. Basketbol hakemlerinin fiziksel öz sayg1 ve alt faktörleri, hakem öz yeterlik ve alt faktörlerinin birbirleriyle ilişkili oldukları görülmüştür.

\section{ÖNERILER}

Bu çalışmada basketbol hakemlerinin pozitif inançlarından mesleki haz ve fiziksel öz saygı konu edilmiştir. Yapılacak başka çalışmalarda hakemlerin diğer pozitif inançlarına yönelik çalışmalar yapılabilir. Ayrıca bu araştırma kapsamında mesleki haz ve fiziksel öz saygı kavramı, bilişsel düzeyde algısal olarak ele alınmıştır. Yapılacak uygulamaya dönük çalışmalar alan yazına katkı sağlayabilir.

\section{KAYNAKLAR}

Adams, G., Turner H., \&Bucks R. (2005). The experience of body dissatisfaction in men. Body Image, 2(3), 271-283. https://doi.org/10.1016/j.bodyim.2005.05.004.

Bandura, A. (1997). Self-efficacy: The exercise of control. New York: Freeman.

Confalonieri, E., Gatti, E., Ionio, C., \& Traficante, D. (2008). Body Esteem Scale: a validation on Italian adolescents. Psychometrics: Methodology in Applied Psychology, 15(3), 153-165.

Dotse, J. E., \& Asumeng, M. (2014). Relationship between body 1mage satisfaction and psychological wellbeing: the impact of africentric Values. Journal of Social Science Studies, 2(1), 320. Doi:10.5296/jsss.v2i1.6843.

Ekmekçi, R. (2008). Basketbol hakemlerinin stres kaynakları ile stresle başa çıkma yöntemlerinin tesbiti ve önleyici yönetsel uygulamaların geliştirilmesi(Unpublished doctoral dissertation). Abant İzzet Baysal Üniversitesi, Bolu.

Ekmekçi, R. (2016). Hakemlikte psikolojik hazırlık. Ankara: Detay Yayıncılık.

Farshad, T., Esmaeili, M. R., \& Bavandpour, R. (2013). The effect of self-efficacy on job satisfaction of sport referees. European Journal of Experimental Biology, 3,2, 219-225.

Feltz, D. L., Short, S. E., \& Sullivan, P. J. (2008). Self-efficacy in sport. Champaign, IL: Human Kinetics.

Fraenkel, J. R., \& Wallen, N. E. (2009). How to design and evaluate research in education (7th ed.). New York: McGraw-Hill.

Guillén, F., \& Feltz, D. L. (2011). A conceptual model of referee efficacy. Frontiers in psychology, 2, 25, 1-5. https://doi.org/10.3389/fpsyg.2011.00025. 
Hepler, T. J., \& Feltz, D. L. (2012). Take the first heuristic, self-efficacy, and decision-making in sport. Journal of Experimental Psychology: Applied, 18(2), 154-161. https://doi.org/10.1037/a0027807.

Karaçam, A. (2016). Beden eğitimi öğretmenlerinin başarı algılarında yordayıcı olarak akademik iyimserlik, psikolojik iyi oluş ve fiziksel saygı. Doktora Tezi. Gazi Üniversitesi, Eğitim Bilimleri Enstitüsü, Ankara.

Karaçam, A. ve Adıgüzel, S. N. (2016). Beden eğitimi öğretmenlerinin fiziksel saygı düzeylerinin incelenmesi. Gaziantep Üniversitesi Spor Bilimleri Dergisi, 1(2), 62-74.

Karaçam, A. ve Pulur, A. (2016). Identification the relation between active basketball classification referees' empathetic tendencies and their problem solving abilities. Universal Journal of Educational Research, 4, 1912 - 1917. https://doi.org/10.13189/ujer.2016.040822.

Karaçam, A. ve Pulur, A. (2017a). Hakem öz yeterlik ölçeği’nin (HÖYÖ) Türkçe’ye uyarlama çalışması. Ömer Halisdemir Üniversitesi Beden Eğitimi ve Spor Bilimleri Dergisi, 11(1), 118-128.

Karaçam, A. ve Pulur, A. (2018). Hakemler için mesleki haz ölçeği: geçerlik ve güvenirlik çalışması-himhö. Gaziantep Üniversitesi Spor Bilimleri Dergisi, 3(2), 35-45. https://doi.org/10.31680/gaunjss.416737.

Karaçam, A., \& Pulur, A. (2017b). Examining the relationship between referee self-efficacy and general selfefficacy levels of football, basketball and handball referees. Universal Journal of Educational Research, 5, 9, 1571-1579. https://doi.org/10.11114/jets.v5i8.2450.

Karaçam, A., \& Pulur, A. (2017c). Examining the relationship between referee self-efficacy and general selfefficacy levels of basketball referees in terms of certain variables. Journal of Education and Training Studies, 5(8), 37-45.

Karaçam, A., Pulur, A. ve Adıgüzel, S. N. (2017). Beden eğitimi öğretmenlerinin mesleki haz ve fiziksel öz saygi düzeyleri arasindaki ilişkinin incelenmesi. Ömer Halisdemir Üniversitesi Beden Eğitimi ve Spor Bilimleri Dergisi, 11(2), 62-74.

Mendelson B.K., Mendelson M. J., \& White D.R. (2001). Body-esteem scale for adolescents and adults. Journal of personality assessment, 76(1): 90-106. https://doi.org/10.1207/S15327752JPA7601_6.

Myers, N. D., Feltz, D. L., Guillén, F., \& Dithurbide, L. (2012). Development of, and initial validity evidence for, the Referee Self-Efficacy Scale: A multistudy report. Journal of sport and Exercise Psychology, 34(6), 737-765.

Schilder, P. (1950). The Image and Appearance of the Human Body New York: Int. J. Univ. Press.

Spencer, B. D. (2015). Self-efficacy and Performance in Volleyball Referees. Michigan State University. Kinesiology.

Tuero, C., Tabernero, B., Marquez, S., \& Guillen, F. (2002). Análisis de los factores que influyen en la práctica del arbitraje [Analysis of the factors affecting the practice of refereeing]. SCAPE, 1(1), 7-16.

Uğur, G. (1996). Üniversite ögrencilerinde atılganlık ile beden alglsı ilişkisi. Yüksek lisans Tezi, Ege Üniversitesi, Sosyal Bilimler Enstitüsü, İzmir. 